\title{
O Projeto de Extensão Unati-Assis em Perspectiva: Trajetória, Desenvolvimento e Ações
}

\author{
The Extention Program Unati-Assis in Perspective: \\ Path, Development and Actions
}

\section{El Proyecto de Extensión Unati-Assis en Perspectiva: Trayectoria, Desarrollo y Acciones}

\author{
(iD) \\ Kátia Rodrigues Mello Miranda \\ Universidade Estadual Paulista Júlio de Mesquita Filho \\ (iD) \\ Laura Pagnan Condini \\ Universidade Estadual Paulista Júlio de Mesquita Filho \\ iD 9 \\ Joyce Máximo de Almeida \\ Universidade Estadual Paulista Júlio de Mesquita Filho
}

Resumo: Este artigo tem por finalidade apresentar o projeto de extensão "Universidade Aberta à Terceira Idade - UNATI", da Faculdade de Ciências e Letras de Assis - UNESP. Para tanto, delineiam-se dados da trajetória da UNATI na unidade (MARTINS, 1997), um panorama de seu funcionamento atual e reflexões sobre a importância de um trabalho como este, tanto para a comunidade interna da universidade como para os idosos da comunidade externa que participam das atividades oferecidas. O projeto conta com uma grande variedade de oficinas, compreendendo âmbitos didáticos, artístico-culturais e a área da saúde, que são ministradas 
semanalmente e visam o desenvolvimento de diferentes aspectos dos participantes (CORREA, 2019). Demonstra-se, ainda, como a UNATI vem suscitando diversos desdobramentos, como pesquisas na graduação e pós-graduação, assim como seus resultados, consolidados em vivências que transformam atividades acadêmicas em experiências afetuosas e fecundas para todos os envolvidos. Palavras-chave: Extensão. Terceira Idade. Oficinas. Pesquisa.

Abstract: This article aspires to present the extension program "Universidade Aberta à Terceira Idade - UNATI", from Faculdade de Ciências e Letras de Assis - UNESP. Therefore, data from UNATI's path in the university campus are presented, as well as an overview of its current functioning and reflections on the importance of a work like this, both for the internal community of the university and for the elderly in the external community who participate in the offered activities. The program has a wide variety of workshops, including in the didatic and artistic-cultural spheres and matters related to health and well being, which are taught weekly and aim at the development of different aspects of the participants. It's also shown how UNATI has been raising several deployments, such as undergraduate and graduate research, as well as its results, consolidated in practices that turn academic activities into affectionate and fruitful experiences for all involved.

Keywords: Extension program. Elderly. Workshops. Research.

Resumen: Este artículo se propone presentar el proyecto de extensión "Universidad Abierta a la Tercera Edad - UNATI", de la Facultad de Ciencias y Letras de Assis - UNESP. Para tanto, se delinean datos de la trayectoria de la UNATI en la unidad, se presenta un panorama de su funcionamiento actual y se realizan reflexiones sobre la importancia de un trabajo como este, tanto para la comunidad interna de la universidad como para los ancianos de la 
comunidad externa que participan de las actividades ofrecidas. El proyecto cuenta con una gran variedad de talleres, que se enmarcan en ámbitos didácticos, artístico-culturales y en el área de la salud, que se imparten semanalmente y se destinan al desarrollo de diferentes aspectos de los participantes. Se demuestra, además, cómo la UNATI viene suscitando diversos despliegues, como investigaciones en las carreras de grado y posgrado, así como sus resultados, consolidados en vivencias que transforman actividades académicas en experiencias afectuosas y fructíferas para todos los participantes.

Palabras clave: Extensión. Tercera Edad. Talleres. Investigación.

Data de submissão: 24/07/2020

Data de aprovação: 01/12/2020

3

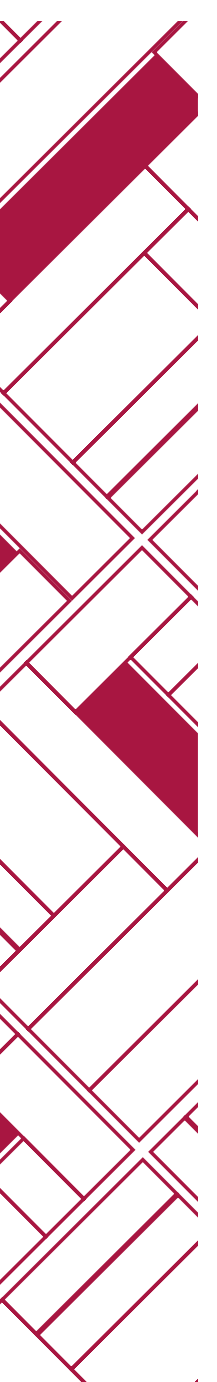




\section{Introdução}

O surgimento de categorias etárias na modernidade relaciona-se ao processo de ordenamento social que gradativamente diferenciou as gerações e especializou funções, hábitos e espaços de acordo com a idade. A formação de novos saberes médicos e a institucionalização das aposentadorias foram determinantes para a noção de velhice que, nesse contexto de segregação, era marcada pela ideia de invalidez, degeneração física, silêncio social, abandono e descaso (SILVA, 2008).

Nessa esteira, o envelhecimento populacional no século $X X$ estabelece uma mudança de perspectiva. Indo ao encontro da tendência na sociedade contemporânea em rever estereótipos negativos associados às diversas velhices existentes (SILVA et al., 2012), a Organização Mundial da Saúde reconhece, em 2002, os direitos humanos das pessoas idosas, durante a elaboração do Plano de Madrid, que promove o envelhecimento ativo baseado no tripé saúde, participação e segurança, com o objetivo de melhorar a qualidade de vida dessa população (DÁTILO; CORDEIRO, 2015).

Entretanto, mesmo com o surgimento de leis que procuram garantir a proteção ao idoso, reverberações da noção de velhice indesejável são facilmente encontrados ainda hoje. O modelo biomédico dominante na definição do envelhecimento como declínio da juventude, que, por sua vez, é referência do que é valorizado, contribui para a marginalização desse grupo, de maneira que os sinais da idade tornam-se marcas de aversão e patologia (MAIA; LONDERO; HENZ, 2008).

A desvalorização da terceira idade está ligada a uma sociedade em que esse segmento, por não ser produtor de riqueza ou consumidor em maior escala, deixa de ter reconhecimento social e passa a ser associado à inutilidade e decrepitude (DAL PICOLO; 
O Projeto De Extensão Unati-Assis Em Perspectiva: Trajetória, Desenvolvimento E Ações Kátia Rodrigues Mello Miranda • Laura Pagnan Condini, et al...

FERNANDES, 2008). Para Correa (2009), o isolacionismo da sociedade contemporânea recai mais intensamente sobre os idosos, que, isolados no espaço doméstico e afastados do mundo do trabalho, da vida social e do lazer, encontram-se com possibilidades reduzidas de contato e apropriação do mundo.

Ainda de acordo com Correa (2009), o trabalho voltado à formação de grupos com a terceira idade permite o enfrentamento da tendência de individualização na atualidade e possibilita o rompimento com a experiência de segregação à qual a população idosa está submetida. Nesse processo, o respeito à autonomia é essencial para uma boa qualidade de vida e pressupõe a superação de estereótipos, assim como a criação de um ambiente acolhedor com escuta e percepção das necessidades físicas e psicológicas do idoso, em que possa manifestar seus anseios e objetivos individuais, sem ser submetido à coação, influência, indução ou intimidação (PETRI, 2018).

Atendendo a determinações legais e, principalmente, à demanda social, ao longo da década de 1990 a Universidade Estadual Paulista "Júlio de Mesquita Filho" - UNESP engendra o projeto de extensão Universidade Aberta à Terceira Idade (UNATI) e o implementa, gradativamente, em vários câmpus, promovendo espaços de socialização e ampliação de conhecimentos. Neste artigo se discorrerá sobre a trajetória e configuração da UNATI na Faculdade de Ciências e Letras de Assis - UNESP, a partir de três eixos: o contexto de surgimento do projeto e seu percurso na unidade; sua estrutura organizacional e administrativa atual e atividades oferecidas; e o espaço de pesquisa proporcionado pelos trabalhos desenvolvidos no âmbito da UNATI. 


\section{O Projeto de Extensão Universidade Aberta à Terceira Idade: Surgimento e Trajetória no Câmpus de Assis}

Em 1987, é regulamentado o Conselho Estadual do Idoso (C.E.I), órgão da Secretaria de Estado do Governo de São Paulo, com a função de formular diretrizes para a implementação de ações voltadas à defesa dos direitos desse grupo. Estabelecem-se também os Núcleos Regionais de Idosos (N.R.I.), com a finalidade de despertar a atenção e o apoio da comunidade regional e local aos cidadãos que envelhecem (MARTINS, 1997).

Antecedendo a Política Nacional do Idoso (BRASIL, 1994) e visando contribuir com reflexões acerca da importância do espaço universitário na discussão sobre a inclusão social e o lugar da veIhice na sociedade, em 1993 a UNESP solicita, por meio do Ofício Circular nº 55/93-PROEX (Pró-reitoria de Extensão Universitária e Cultura), a análise e manifestação de suas unidades sobre a proposta inicial do chamado Workshop Projeto Sênior. Realizado em 1994, esse trabalho buscou debater com a comunidade acadêmica sobre o envelhecimento humano, expectativas e propostas para atividades voltadas à terceira idade. Posteriormente, com apoio da PROEX, as unidades universitárias da UNESP comprometeram-se com o projeto então denominado "Universidade Aberta à Terceira Idade" - UNATI, incentivando a implantação de atividades e o fortalecimento de práticas existentes desde 1995 (DÁTILO; CORDEIRO, 2015).

Com o crescimento das ações e a necessidade de integração, criou-se em 2001 o Núcleo Central UNATI, vinculado à PROEX, responsável pela coordenação, suporte e orientação do projeto nas diferentes unidades da UNESP, mas ainda mantendo a autonomia de cada Núcleo Local, que desde então conta com coordenação e vice. Em 2003, a UNATI passou a compor o Programa UNESP de Integração Social e Comunitária (PISC). 
O Projeto De Extensão Unati-Assis Em Perspectiva: Trajetória, Desenvolvimento E Ações Kátia Rodrigues Mello Miranda • Laura Pagnan Condini, et al...

Em Assis, a UNATI passou a funcionar como projeto de extensão em 1994, sob coordenação da Dra. Edna Julia Scombatti Martins, do Departamento de Psicologia Evolutiva Social e Escolar da UNESP, após envolvimento anterior da docente com o público da terceira idade do município por meio do Núcleo do Idoso e pelo oferecimento de um estágio em postos de atendimento desde 1990.

Tendo o câmpus já manifestado junto ao Núcleo do Idoso de Assis a intenção de trabalhar com tal público, fez-se necessária a sensibilização da comunidade universitária para que as atividades fossem incorporadas. Após uma reunião entre as chefias de departamento da unidade iniciou-se o processo para a formação de um Grupo de Trabalho com a então secretária municipal de Ação e Desenvolvimento Social, o vice-presidente do Núcleo do Idoso de Assis e docentes que desenvolviam ações com particularidades que agregariam àquilo que se desejava colocar em prática no projeto. Esse grupo foi responsável pela divulgação da iniciativa por meio de eventos e atividades de curta duração e, a partir das respostas obtidas por um questionário, percebeu-se o desejo dos participantes pela aquisição de novos conhecimentos aliada à oportunidade de executar atividades artísticas (MARTINS, 1997).

Assim constituiu-se a UNATI em Assis, que nos últimos anos conta com uma média de 90 voluntários, compreendendo tanto a comunidade interna do câmpus (discentes da graduação e pós, servidores e docentes) quanto externa (profissionais de diversas áreas, como saúde, esportes e artesanato), e atende cerca de 300 alunos da terceira idade, distribuídos em mais de trinta oficinas de natureza variada oferecidas todo ano.

O projeto de extensão, ao favorecer a atualização de conhecimentos gerais e específicos, que confluam com os interesses dos idosos, e ao promover um espaço de convivência e troca de experiências, tem como objetivos primordiais a reinserção sociocomu- 
O Projeto De Extensão Unati-Assis Em Perspectiva: Trajetória, Desenvolvimento E Ações Kátia Rodrigues Mello Miranda • Laura Pagnan Condini, et al...

nitária, o resgate da identidade e a valorização da sensibilidade e autoestima, resultando na construção de uma autoimagem positiva (MARTINS, 1997).

Para Martins (1997), a memória do idoso é um veículo transmissor de experiências e valores de uma cultura e, em uma sociedade segmentada por etariedade, a universidade é um local privilegiado para o convívio entre gerações e oportunidades de encontros. A proposta do oferecimento de atividades a quem envelhece deve envolver todos os voluntários interessados em dignificar a vida do outro, num processo de reflexão e adaptação ao crescimento do contingente de pessoas idosas, e com flexibilidade e complementaridade suficientes para atender às necessidades do grupo em questão. Dessa forma, a UNATI procura trazer a comunidade externa da terceira idade para o ambiente universitário, de maneira a propiciar um estreitamento da relação entre os discentes e a população idosa de Assis e região.

\section{Unati-Assis: Estrutura Administrativa e Oficinas}

Na UNESP de Assis, a UNATI oferece oficinas de temáticas diversas e acolhe, anualmente, entre 250 e 300 alunos de Assis e região, com idade superior a 50 anos. Para matricular-se, após cadastramento, o aluno escolhe em quais oficinas deseja participar e opta por quantas quiser, desde que não haja conflito de horários. O dia e o número de vagas disponíveis para cada oficina são determinados pelos oficineiros de acordo com sua disponibilidade e buscando o melhor ordenamento para que os participantes, caso desejem, possam frequentar várias aulas. Há a possibilidade de criação de uma lista de espera e as vagas remanescentes podem ser preenchidas posteriormente, mediante contato com a equipe administrativa e responsáveis pela oficina. 
O Projeto De Extensão Unati-Assis Em Perspectiva: Trajetória, Desenvolvimento E Ações Kátia Rodrigues Mello Miranda • Laura Pagnan Condini, et al...

A frequência dos alunos da terceira idade no câmpus permite que sejam reconhecidos pela comunidade universitária, de maneira que ocorra uma interação tanto na informalidade, em diferentes ambientes, como por meio das oficinas (CORREA; JUSTO, 2010). Os oficineiros, em sua maioria, são graduandos dos cursos de Letras, Psicologia e História, alguns funcionários do câmpus e colaboradores da região, que se voluntariam para oferecer aulas semanais. As oficinas têm duração de 1 h30 e são realizadas no período da tarde, de segunda a sexta-feira.

A UNATI conta com algumas parcerias que expandem a diversidade de suas ações. Uma delas é com o Programa Agita Assis, desenvolvido pela prefeitura municipal, que disponibiliza oficinas de esportes no período da manhã, duas vezes por semana, e visa combater o sedentarismo e estimular a prática da atividade física de forma regular. Outras parcerias ocorrem com a Associação Acadêmica Atlética XVI de Agosto, que, além de fornecer materiais para a realização de algumas oficinas, promove encontros mensais com atividades de alongamento, caminhada e piquenique nos espaços do câmpus, e com uma universidade privada de Assis, que oferece oficinas de Fisioterapia, como estágio prático de seus alunos. Há, ainda, parcerias ocasionais com outros projetos de extensão da unidade, como o "Bicho-Folha", executado por alunos do curso de Ciências Biológicas, que participa em eventos da UNATI com o intuito de popularização da ciência e divulgação de conhecimentos regionais, e o "Coral da Multiplicidade", muito atuante em ensaios, performances e apresentações dos alunos.

Além das atividades semanais, a equipe administrativa organiza confraternizações entre alunos e oficineiros, como as já tradicionais festas junina, de celebração de dia das mães e dia dos pais, de encerramento do ano letivo, e também tardes de filmes com discussões, encontros culturais de línguas estrangeiras, exposi- 
O Projeto De Extensão Unati-Assis Em Perspectiva: Trajetória, Desenvolvimento E Ações Kátia Rodrigues Mello Miranda • Laura Pagnan Condini, et al...

ções e outros espaços em que os alunos da terceira idade possam apresentar trabalhos e habilidades, socializar-se e divertir-se com peças de teatro e apresentações artísticas.

A equipe administrativa atual é composta por uma docente do câmpus como coordenadora geral e uma funcionária como vice-coordenadora, uma aluna bolsista responsável pelas ações de secretaria e outros nove alunos da graduação, dos cursos de Psicologia, Letras e História. O grupo se organiza em plantões e fica à disposição dos oficineiros durante o período das aulas, auxiliando em ações primordiais como o contato com alunos, a organização de salas, matrículas e materiais, além de responsabilizar-se pela resolução de eventuais problemas nas atividades diárias. O projeto como um todo, assim como os eventos realizados, conta com o apoio da Direção da unidade e de alguns funcionários, professores e seções técnicas e administrativas, que oferecem suporte para o melhor atendimento aos idosos.

As oficinas ofertadas nos últimos anos podem ser divididas em três grandes grupos: as didáticas, as artístico-culturais e as que abrangem a área da saúde e bem-estar. As didáticas contemplam a alfabetização e o ensino de línguas estrangeiras (inglês, espanhol, alemão, francês, japonês e italiano) em diferentes níveis (do básico ao avançado). Como no câmpus há o curso de licenciatura em Letras, tais oficinas são tradicionais na UNATI, têm bastante procura e voltam-se a práticas culturais e à exploração das habilidades linguísticas. Entre os idosos, a busca pelo aprendizado de idiomas e, consequentemente, pela educação, torna-se necessária por diversos motivos, como o intuito de realizar viagens, a apreciação cultural, a integração social e a "ginástica mental" inerente a essa esfera de estudos, que estimula a cognição (CARDOSO, 2014). Cabe salientar que as oficinas de línguas estrangeiras são campo de desenvolvimento do estágio docente pelos graduandos, 
O Projeto De Extensão Unati-Assis Em Perspectiva: Trajetória, Desenvolvimento E Ações Kátia Rodrigues Mello Miranda • Laura Pagnan Condini, et al...

que ministram as aulas em duplas e são supervisionados por um coordenador do respectivo idioma.

A UNESP de Assis possui, ainda, um núcleo do Projeto de Educação de Jovens e Adultos (PEJA), em que alunos de diferentes cursos de graduação participam dando aulas em alguns pontos da cidade e região, sendo a UNATI um dos polos de atuação com a oficina de Letramento e Reforço. De acordo com Soares e Istoe (2015), a população idosa apresenta uma taxa mais elevada de analfabetismo, acarretando maior dependência e exclusão social. A educação ocupa, portanto, papel fundamental no processo de envelhecimento, promovendo transformações sociais e favorecendo a formação crítica do idoso, para que tenha condições de manter-se ativo, exigindo mais respeito, dignidade e o cumprimento de seus direitos.

No viés de inclusão social, a UNATI também oferece oficinas voltadas à tecnologia, como as de Informática Básica e Introdução ao Smartphone, que, anualmente, figuram entre as mais procuradas e de maior assiduidade dos alunos. As aulas são ministradas de forma prática, dinâmica, e, por vezes, contam com um número maior de oficineiros, a fim de fornecer um acompanhamento mais próximo aos participantes, no manejo dos computadores e celulares.

$\mathrm{Na}$ área da saúde, as oficinas oferecidas, com a finalidade de promover o bem-estar do corpo e da mente, são: Encontros com a Terceira Idade, Resgate e Ressignificação de Memórias, Autobiografia, Alimentação Saudável, Tênis de Mesa, Fisioterapia, Pilates, Relaxamento e Bem-estar, Yoga e Agita Assis (Esporte). Diversos estudos (BENEDETTI, 2008; MACIEL, 2010, entre outros) mostram a importância da relação entre saúde mental e atividade física para a população idosa. Assim, muitos alunos buscam o projeto com o intuito de realizar algum exercício físico ou alcançar hábitos mais 
O Projeto De Extensão Unati-Assis Em Perspectiva: Trajetória, Desenvolvimento E Ações Kátia Rodrigues Mello Miranda • Laura Pagnan Condini, et al...

saudáveis, encontrando nessas oficinas um espaço com tutores preparados e disponíveis aos interesses e limitações individuais.

O último grupo de oficinas proporciona expressões no âmbito artístico-cultural, como as oficinas de Compreensão da América Latina por meio de Práticas Culturais, Capoeira Angola, Danças (do ventre, de salão e ballet), Teatro, Automaquiagem, Sentidos do Corpo, Jogos da Mente e Concentração, Seresta, Jogos de Salão e Artesanato (desenho, artes manuais e arraiolo, entre outros).

As artes, em suas variadas formas, potencializam a comunicação, a iniciativa, a criatividade e a descoberta dos interesses e aptidões do "eu", além de serem imprescindíveis para o desenvolvimento de aspectos como discurso, imaginação, emoção, capacidade de simbolização, autoestima, autonomia e sentimento de empatia - aspectos de grande relevância para uma melhor qualidade de vida na terceira idade (FONTES, 2015).

Para a contínua adaptação das práticas às necessidades dos participantes, mantém-se aberto um espaço de sugestões e opiniões. Nos relatos dos alunos destacam-se aspectos como a boa convivência, a realização de atividades às quais muitos não teriam acesso se não fosse pelo projeto, possibilitando o desenvolvimento da educação formal e o aproveitamento de experiências em um ambiente dedicado à terceira idade, benefícios em relação à autoestima e às habilidades motoras, e, em síntese, o impacto da UNATI na rotina, no sentimento de renovação e qualidade de vida dos idosos atendidos.

Com a necessidade de isolamento social devido à pandemia causada pela COVID-19 a partir de março de 2020, as atividades presenciais da UNATI foram suspensas. Compreendendo a importância de manter o vínculo com os alunos e de proporcionar um espaço proveitoso de aprendizado e compartilhamento de experiências, especialmente no cenário atual em que o contato físico 
O Projeto De Extensão Unati-Assis Em Perspectiva: Trajetória, Desenvolvimento E Ações Kátia Rodrigues Mello Miranda • Laura Pagnan Condini, et al...

não é possível, o projeto permaneceu ativo pela modalidade online. Após divulgação pela página da UNATI no Facebook, foram criados grupos no Whatsapp para que os oficineiros e alunos, que tivessem interesse e condições de participar nessa configuração, prosseguissem com as atividades.

\section{Unati-Assis: Espaço de Pesquisa e Presença do Curso de Psicologia}

Além de caracterizar-se como um espaço de ensino, aprendizagem, trocas e formação de vínculos entre os oficineiros e os idosos, a UNATI também contribui para o aperfeiçoamento de aprendizados inerentes a cada oficina e o desenvolvimento acadêmico dos discentes do câmpus ao possibilitar a realização de pesquisas.

Do trabalho realizado na UNATI de Assis, no âmbito da graduação surgiram diversos artigos, relatos de experiências, apresentações em eventos e projetos de iniciação científica, contemplando variadas abordagens e áreas do conhecimento, como métodos de ensino em línguas estrangeiras para idosos e possibilidades de diálogo intergeracional, dentre outras (MIRANDA et al., 2020; CORREA, 2019; GERALDI, 2015; DONÁ et al., 2015; CUNHA et al., 2013; MONTEIRO, 2013; CRUZ et al., 2011; SANTOS et al., 2011; ARAl; et al., 2011; CORREA; JUSTO, 2010; COELHO, 2009, para citar alguns exemplos).

A UNATI também faz parte da trajetória de diversos discentes que, finalizada a graduação, em sua vida profissional e acadêmica mantiveram-se ligados à temática do envelhecimento, que já foi objeto de estudo do Programa de Pós-Graduação em Psicologia do câmpus de Assis (SILVA, 2019; GEROLAMO, 2019; SABBADINI, 2019; ROZENDO, 2013), ratificando, também nessa esfera de pesquisa, a efetividade e impacto dos diálogos construídos no contexto do projeto e sua reverberação na vida dos participantes. 
O Projeto De Extensão Unati-Assis Em Perspectiva: Trajetória, Desenvolvimento E Ações Kátia Rodrigues Mello Miranda • Laura Pagnan Condini, et al...

Os estudos sobre envelhecimento estão bastante presentes na área de Psicologia da UNESP de Assis, exercendo grande influência na formação crítica dos discentes e integrando o trabalho realizado na UNATI por meio de oficinas que são coordenadas por pesquisadores de mestrado e doutorado (Encontros com a Terceira Idade e Automaquiagem) e por discentes da graduação em Psicologia (Sentidos do Corpo, Jogos da Mente e Concentração, Teatro, Ballet, Meditação, Relaxamento e Bem-estar, entre outras).

O câmpus é um dos pioneiros no oferecimento do estudo sobre envelhecimento e finitude como disciplina na grade curricular, sob coordenação atual da Dra. Mariele Rodrigues Correa, também responsável pelo desenvolvimento de pesquisas na Pós-Graduação com essa temática. Com supervisão da docente, há uma ênfase na graduação, intitulada "Envelhecimento e processos de subjetivação", cujos estagiários são responsáveis pela organização de duas oficinas da UNATI: a já mencionada Encontros com a Terceira Idade, que propõe rodas de conversa sobre temas levantados pelos participantes, possibilitando a interação e o surgimento de novos sentidos, e a oficina Idosos Asilados, realizada com idosos institucionalizados que se deslocam até a universidade e que busca, a partir de atividades como pintura, música, fotografia e jogos, sair da lógica da instituição e possibilitar um espaço “onde a lentidão não seja impotência, onde a diferença de ritmos não seja disritmia, onde os movimentos não ganhem sentido apenas em seu desfecho" (PELBART, 1993, p. 41 apud MAIA et al., 2008, p. 52).

Para Dal Picolo e Fernandes (2008), o isolamento e a perda de identidade social na velhice estão associados à depressão e o trabalho em grupo possibilita um espaço de convívio que auxilia o reaprendizado do relacionamento interpessoal, a maximização de habilidades e a preservação da independência e autonomia, visando a reflexão e ressignificação capaz de restituir vitalidade ao idoso. 
O Projeto De Extensão Unati-Assis Em Perspectiva: Trajetória, Desenvolvimento E Ações Kátia Rodrigues Mello Miranda • Laura Pagnan Condini, et al...

Sob esse prisma, o exercício da reconstrução de fatos da memória e da linguagem, além de preventivo a doenças degenerativas, é um "trabalho de subversão de paradigmas que alienam o sujeito de sua história, ou, ainda, de enfrentamento da velocidade e da fugacidade da vivência do tempo na atualidade" (CORREA; JUSTO, 2010, p. 253). Oficinas como Resgate e Ressignificação de Memórias (atividades artísticas e diálogos que trazem ao presente as lembranças e sentimentos do passado) e Autobiografia (narrar ao grupo e escrever a própria história) possibilitam o contato com o processo de construção identitária e trazem de volta o sentimento de pertença a uma história e à sociedade - algo que muitas vezes é expropriado dos mais velhos. Nesses trabalhos, a evocação de uma lembrança pode ocasionar o surgimento de novos significados, sensações e sentimentos, pois, "lembrar não é reviver, mas refazer, reconstruir, repensar, com imagens e ideias de hoje, as experiências do passado. A memória não é um sonho, é trabalho" (BOSI, 1985, p. 17 apud CORREA; JUSTO, 2010, p. 251).

Como materialização do exercício de retomada e reconstrução de narrativas sobre a própria vida, a oficina de Autobiografia realizou, no ano de 2019, com a mobilização de oficineiros, da equipe administrativa da UNATI-Assis e da diretoria do câmpus, a impressão em livro da autobiografia escrita pela participante Maria de Fátima Mendes, de 66 anos, que relatou sempre ter tido vontade de escrever a própria história, manifestou sua gratidão pelo incentivo encontrado e, em especial, as oficineiras, por auxiliarem-na a concretizar algo tão desejado (MENDES, 2019). A produção teve seu desfecho durante a semana de comemoração dos 25 anos da UNATI-Assis, quando a aluna autora pôde falar sobre seu livro, suas histórias e a importância do projeto em sua vida, ofertando algumas cópias impressas aos presentes. 


\section{Relembrar e Comemorar: 25 Anos da Unati-Assis}

Em 2019, a UNATI completou 25 anos na UNESP de Assis, duração que evidencia o sucesso desse projeto de reconhecida incidência na vida e na formação de seus participantes e colaboradores, que cumpre com a responsabilidade da universidade pública no retorno social, oferecendo serviços acessíveis e de qualidade para a população. O marco foi relembrado ao longo do ano e no mês de novembro houve uma semana especial de celebrações, encerrada com uma grande festa.

As atividades comemorativas contaram com aulas abertas das oficinas de Relaxamento e Bem-Estar e Jogos da Mente e Concentração. Em parceria com o "Projeto Bicho-Folha", foram expostos banners com informações sobre a fauna e a flora regional, além da apresentação de insetos e plantas coletados e pequenos organismos que podiam ser vistos pelo microscópio, sob orientação dos alunos responsáveis. Também foi realizada a roda de conversa "Envelhe(s)cendo com a UNATI-Assis: sonhos, memórias e conquistas", conduzida pelos docentes Dra. Mariele Rodrigues Correa e Dr. José Justo Sterza, ex-coordenador da UNATI, em que discorreram sobre a influência do trabalho efetuado no projeto em sua vida profissional e pessoal, suscitando a reflexão e o compartilhamento de lembranças e experiências com alunos da terceira idade presentes.

A semana de festividades foi marcada, ainda, pela inauguração de um espaço designado à UNATI, projetado pensando nas necessidades das oficinas artístico-culturais e equipada com materiais apropriados. A sala recebeu o nome da docente aposentada "Dra. Edna Julia Scombatti Martins", homenageada como uma das fundadoras do projeto e pioneira na atuação com a terceira idade na UNESP de Assis, conforme mencionado antes. 
O Projeto De Extensão Unati-Assis Em Perspectiva: Trajetória, Desenvolvimento E Ações Kátia Rodrigues Mello Miranda • Laura Pagnan Condini, et al...

A cerimônia de inauguração contou com discursos da então diretora do câmpus, Dra. Andrea Lúcia Dorini de Oliveira Carvalho Rossi, da vice-diretora e então coordenadora da UNATI Dra. Cátia Inês Negrão Berlini de Andrade e do Dr. Carlos Erivany Fantinati, diretor da unidade na época em que o projeto teve início. Os discursos ressaltaram a importância da iniciativa em tornar a universidade acessível para pessoas da terceira idade e a relevância da recuperação da memória do projeto como uma forma de perpetuação. Ainda, o discurso da docente homenageada relembrou aspectos da trajetória e dificuldades da UNATI desde a sua criação e a necessidade de adaptação, com o passar dos anos, para a manutenção do objetivo de atender aos anseios e necessidades dos alunos.

No dia 22 de novembro, a aguardada festa de comemoração marcou também o fim do ano letivo da UNATI com diversas apresentações e uma grande confraternização. O Salão de Atos, principal auditório da unidade, foi especialmente decorado e o evento foi transmitido pelo Facebook, com apoio técnico da STAEPE (Seção Técnica de Apoio ao Ensino, Pesquisa e Extensão). A noite foi marcada por várias apresentações organizadas pelas oficinas de Teatro, Introdução ao Smartphone, Seresta, Línguas Estrangeiras e Jogos da Mente e Concentração, assim como por discursos da coordenação, coroando duas décadas e meia de um projeto prolífico e que busca a cada ano o aprimoramento de sua atuação no atendimento da comunidade idosa de Assis e região.

\section{Considerações Finais}

A UNATI-Assis vem há 25 anos oferecendo um amplo leque de atividades gratuitas para a população da terceira idade. Por meio de práticas educativas multidisciplinares, o projeto visa contribuir para a melhora da qualidade de vida do seu público-alvo, 
O Projeto De Extensão Unati-Assis Em Perspectiva: Trajetória, Desenvolvimento E Ações Kátia Rodrigues Mello Miranda • Laura Pagnan Condini, et al...

considerando aspectos como a marginalização de idosos e o lugar privilegiado que a universidade ocupa na possibilidade de aquisição e desenvolvimento de conhecimentos, além dos benefícios gerados na construção da identidade tanto dos alunos como dos oficineiros, que, muitas vezes, encontram nessa experiência encaminhamentos profissionais e acadêmicos.

As oficinas configuram um espaço de práticas diversas, viabilizando o aprendizado mútuo e a valorização de saberes - sejam estes produzidos, resgatados, aprimorados, ampliados ou ressignificados. Além de fomentar o crescimento pessoal a partir de experiências pautadas na intergeracionalidade e criar um ambiente acolhedor, com escuta e percepção sensíveis às necessidades dos idosos, o projeto promove aos oficineiros a oportunidade de desenvolvimento acadêmico, com novas possibilidades de pesquisas, ensino e didática flexível, adaptadas aos contextos específicos dos alunos.

A UNATI busca atribuir à velhice um olhar não equiparado ao declínio da juventude de maneira patológica, mas sim de compreensão acerca da heterogeneidade das diversas formas de existência e vivências pertinentes ao envelhecimento. Desse modo, prioriza-se a abordagem das capacidades individuais, estimulando o resgate identitário, a valorização da experiência, dos saberes, da sensibilidade e a elaboração de uma autoimagem positiva com respeito à autonomia do idoso.

Os resultados que o projeto vem apresentando ao longo de seus 25 anos corroboram a potencialidade da interação entre gerações, ocasionando reflexões e aprendizado entre os participantes (seja em âmbito pessoal, acadêmico ou profissional), que de tal encontro constroem desde saberes científicos até laços duradouros. Além disso, é possível destacar a universidade como local de produção de conhecimento, influência social e importância 
O Projeto De Extensão Unati-Assis Em Perspectiva: Trajetória, Desenvolvimento E Ações Kátia Rodrigues Mello Miranda • Laura Pagnan Condini, et al...

para a realização de trabalhos com a terceira idade, no combate à tendência atual de individualização e segregação por etariedade, promovendo a reinserção sociocomunitária desse grupo marginalizado.

Cabe ao ambiente acadêmico promover reflexões, ações e discussões acerca de temas preponderantes como o envelhecimento populacional e as diversas velhices existentes, assim como buscar novos olhares e planos de ação, de modo a melhor adaptar-se às necessidades de seus participantes. Nessa direção, atualmente, em face do cenário de isolamento social imposto pela pandemia da COVID-19, o projeto mantém seu compromisso, oferecendo o suporte possível ao público da terceira idade neste momento em que as dificuldades são potencializadas.

A comemoração dos 25 anos da UNATI na UNESP de Assis reitera o mérito de ações extensionistas comprometidas e de impacto, para a consolidação do vínculo entre a universidade e a comunidade, bem como a manutenção do canal aberto de benefício mútuo entre elas.

\section{Referências}

ARAI, R. Y. et al. Universidade Aberta À TercelRa IdAde: promoção e ValorlzaçÃo de qualidade de vida aOs Idosos. Anais do $6^{\circ}$ Congresso de Extensão Universitária da UNESP, Águas de Lindoia. São Paulo: PROEX; UNESP, 2011, P. 1069. DISPONIVEL EM: HTTPS://REPOSITORIO.UNESP.BR/BITSTREAM/HANDLE/11449/145621/ISSN21769761-2011-06-1069.PDF?SEQUENCE=1. ACESSO EM: 10 ABR. 2020.

BENEDETTI, T. R. B. et al. Atividade física e estado de Saúde mental de IDOsos. Revista de Saúde Pública, v. 42, N. 2, 2008, p. 302-307. Disponível em: HTTPS://WwW.SCIELO.BR/PDF/RSP/V42N2/6482.PDF. ACESSO EM: 09 ABR. 2020. 
O Projeto De Extensão Unati-Assis Em Perspectiva: Trajetória, Desenvolvimento E Ações Kátia Rodrigues Mello Miranda • Laura Pagnan Condini, et al...

BRASIL. Lei nº 8.842, de 4 de janeiro de 1994. Dispõe sobre a Política NaCIONAL DO IDOSO, CRIA O CONSELHO NACIONAL DO IDOSO E DÁ OUTRAS PROVIDÊNCias. Diário Oficial da União, 1994. Disponível em: htTp://WwW. Planalto. GOV.BR/CCIVIL_03/LEIS/L8842.HTM. ACESSO EM: 07 ABR. 2020.

CARDOSO, J. dA S. et AL. AprendizAgem de IDIOMAS NA TeRCEIRA IDADE: MUITO ALÉM DE UM PASSATEMPO. LiNGUAGEM, TEORIA, ANÁLISE E APLICAÇões, V. 8, 2014. P. 73-89. DISPONÍVEL EM: HTTP://WWW.PGLETRAS.UERJ.BR/LINGUISTICA/ TEXTos/LIVRO08/LTAA8_A05.PDF. ACESSO EM: 15 ABR. 2020.

COELHO, A. P. D. M. V. ET AL. O ENSINO DE LíngUA INGLESA PARA A TERCEIRA IDADE NO PROJETO UNIVERSIDADE ABERTA À TERCEIRA IDADE NO CÂMPUS DE AsSIS: uma experiênCia em Sala de aula. Anais do $5^{\circ}$ Congresso de Extensão Universitária, Águas de Lindoia. São Paulo: PROEX; UNESP, 2009, P. 436. DisPONÍVEL EM: HTTP://HDL.HANDLE.NET/11449/147534. ACESSO EM: 10 ABR. 2010.

CORREA, M. R. A Psicologia na Universidade Aberta À Terceira Idade: EXPERIÊNCIAS DE ATUAÇÃO COM IDOSOS NA UNATI/UNESP, CÂMPUS de AsSIS.

Olhar de Professor, N. 19, v. 2, 219-227, 2019. Disponível em: htTPS://ReVISTAS.APPS.UEPG.BR/INDEX.PHP/OLHARDEPROFESSOR/ARTICLE/VIEW/12088. ACESSO EM: 20 ABR. 2020.

CORREA, M. R. Cartografias do envelhecimento na contemporaneidade: Velhice e terceira idade. São Paulo: Cultura Acadêmica, 2009.

CORREA, M. R.; JUSTO, J. S. OfICINAS DE PSICOLOGIA: MEMÓRIA E EXPERIÊNCIA narRativa com idosos. Estudos Interdisciplinares em Psicologia, v. 1, N. 2, P. 249-256, 2010. DiSPONÍVEL EM: HTTP://HDL.HANDLE.NET/11449/126855. ACESSO EM: 10 ABR. 2020.

CRUZ, L. P. da et al. Oficina de Psicologia na UnATI: possibilidade para um diálogo intergeracional. Anais do $6^{\circ}$ Congresso de Extensão UniversI- 
O Projeto De Extensão Unati-Assis Em Perspectiva: Trajetória, Desenvolvimento E Ações Kátia Rodrigues Mello Miranda • Laura Pagnan Condini, et al...

tária da UNESP, ÁguAS de LindoIA. SÃo PAULO: PROEX; UNESP, 2011, P. 967. DisPonível EM: HTTP://HDL.HANDLE.NET/11449/146633. ACESSO EM: 10 ABR. 2020.

CUNHA, L. C. M. DA; SOUSA, P. DE; ROSA, H. R. INTERCÂMBIO DE GERAÇÕES: A CONSTRUÇÃO DE NOVAS REFLEXÕES A PARTIR DAS TROCAS ENTRE ALUNOS E integrantes da UNATI. Anais do $7^{\circ}$ Congresso de Extensão Universitária da UNESP, ÁGuas de Lindoia. São Paulo: PROEX; UNESP, 2013, P. 9136. DisPONÍVEL EM: HTTP://HDL.HANDLE.NET/11449/146899. ACESSO EM: 10 ABR. 2020.

DAL PICOLO, C. C. R.; FERNANDES, B. S. Re-SIGNIFICANDO O GRUPO E A VelHice. Revista da SPAGESP, v. 9, N. 2, P. 50-55, 2008. Disponível em: HTTPS://DIALNET.UNIRIOJA.ES/SERVLET/ARTICULO?CODIGO=5535417. ACESSO EM: 20 ABR. 2020.

DÁtilo, G. M. P. de A.; CORdeiRO, A. P. (Org.). Envelhecimento humano: diferentes olhares. Marília: Oficina Universitária; São Paulo: Cultura ACADÊMICA, 2015.

DONÁ, D. C.; RAMOS, L. C.; PANDOLFI, M. A. O ENSINO-APRENDIZAGEM DE ESPANHOL NA TERCEIRA IDADE. $8^{\circ}$ Congresso de EXTENSÃo UNIVERSITÁRIA DA UNESP, ÁGUAS de LiNDOIA. SÃo PAULO: PROEX; UNESP, 2014, P. 1-4, 2015. DisPoníveL EM: HTTP://HDL.HANDLE.NET/11449/142268. ACESSO EM: 10 ABR. 2020.

FONTES, A. As ARTES ENQUANTO ESTRATÉGIAS DE INTERVENÇÃO DA ANIMAÇÃO sociocultural na terceira idade. Rede Iberoamericana de Animação Sociocultural, Escola Superior de Educação e Ciências Sociais/IPLeiria, N. 22, P. 1-13, 2015.

GERALDI, A. V. B. ET AL. UniversidAde ABERTA À TERCEIRA IDADE: RELATO DE EXPERIÊNCIA DA UNATI AsSIS. $8^{\circ}$ CongRESSO DE EXTENSÃo UNIVERSITÁRIA DA UNESP, ÁguAs de LindoIA. SÃo PAULO: PROEX; UNESP, 2014, P. 1-4, 2015. 
O Projeto De Extensão Unati-Assis Em Perspectiva: Trajetória, Desenvolvimento E Ações Kátia Rodrigues Mello Miranda • Laura Pagnan Condini, et al...

DisPonível EM: HTTP://HDL.HANDLE.Net/11449/142282. ACESSO EM: 10 ABR. 2020.

GEROLAMO, J. C. O tempo nÃo PARA: O ENVELHECIMENTO FEMININO COMO ATO revolucionário. Dissertação (Mestrado em Psicologia). Universidade Estadual Paulista "Júlio de Mesquita Filho", Faculdade de Ciências e Letras de Assis, 2019. 227 F. DisPonívEL EM: HTTP://HDL.HANDLE.NET/11449/191056. ACESSO EM: 18 ABR. 2020.

MACIEL, M. G. Atividade física e funcionalidade do idoso. Motriz: ReVista de Educação Físıca, Rıo Claro, v. 16, n. 4, p. 1024-1032, out./dez. 2010. DISPONIVEL EM: HTTPS://WWW.SCIELO.BR/PDF/MOTRIZ/V16N4/A23V16N4.PDF. ACESSO EM: 10 ABR. 2020.

MAIA, G. F. DA; LONDERO, S.; HENZ, A. DE O. VelHiCE, INSTITUIÇÃO E Subjetividade. Interface-Comunicação, Saúde, Educação, v. 12, N. 24, P. 49-59, JAN./MAR. 2008. DISPONÍVEL EM: HTTPS://SCIELOSP.ORG/PDF/ICSE/2008. V12N24/49-59/PT. ACESSO EM: 15 ABR. 2020.

MARTINS, E. J. S. De volta À ESCOLA: INVESTINDO EM UMA PROPOSTA DE UNIVersidade Aberta À Terceira Idade. Tese (Doutorado em Educação). Marília: UNESP - Faculdade de Filosofia e CiênCIas de Marília, 1997.

MENDES, M. de F. Minhas memórias. UNESP - Faculdade de CiênCias E Letras de Assis: UNATI/PROEX/FUNDUNESP, 2019.

MIRANDA, K. R. M.; VIEIRA, J.; OLIVEIRA, B. C. A literatura do ensino DE ESPANHOL COMO LÍNGUA ESTRANGEIRA NA UNATI (UNESP-ASSIS). IN: LIMA, A. M. De. S. et al. (Org.). Anais da IV Jornada Internacional Brasil - ArGENTINA (JIBA): PESQUISA E ENSINO NA FORMAÇÃO DE PROFESSORES DE SOCIOLOGIA e de Letras-Espanhol. Universidade Estadual de Londrina, 2020. No prelo. MONTEIRO, C. A. et AL. GRupos com terceira IDAdE E IDOSOS ASILAdOS NA UNATI/Assis. Anais do $7^{\circ}$ Congresso de Extensão Universitária da UNESP, Águas de Lindoia. São Paulo: PROEX; UNESP, 2013, P. 9935. Dis- 
O Projeto De Extensão Unati-Assis Em Perspectiva: Trajetória, Desenvolvimento E Ações Kátia Rodrigues Mello Miranda • Laura Pagnan Condini, et al...

PONÍVEL EM: HTTP://HDL.HANDLE.NET/11449/146939. ACESSO EM:120 ABR. 2020.

PetRi, M. C. V. Autonomia e empoderamento dos idosos. Revista Longeviver; Revista Portal de divulgação, N. 57, ANo IX, JUl./Ago./set. 2018, P. 63-69. DisPONÍVEL EM: HTTPS://REVISTALONGEVIVER.COM.BR/INDEX.PHP/REVISTAPORTAL/ARTICLE/VIEW/729/792. ACESSO EM: 20 ABR. 2020.

Rozendo, A. da S. Protagonismo político e social na velhice. Tese (Doutorado em Psicologia). Universidade Estadual Paulista “Júlio de MesQuita Filho", Faculdade de Ciências e Letras de Assis, 2013. 198 f. Disponível EM: HTTP://HDL.HANDLE.NET/11449/105620 ACESSO EM: 18 ABR. 2020.

SABBADINI, A. Mortes Na VIDA E VIDAS NA MORTE: ANÁLISE DE VIVÊNCIAS DE Perdas e lutos em idosos Residentes em Asilo. Dissertação (Mestrado em Psicologia). Universidade Estadual Paulista “Júlio de Mesquita Filho", FaculdAdE De CiênCIAS E Letras de Assis, 2019. 129 F. Disponível EM: HTtP://HDL. HANDLE.NET/11449/190980. ACESSO EM: 18 ABR. 2020.

SANTOS, D. A. dos et al. Primaveras. Anais do $6^{\circ}$ Congresso de Extensão Universitária da UNESP, ÁGUAS de Lindoia. São PAUlo: PROEX; UNESP, 2011, P. 250. DISPONÍVEL EM: HTTPS://REPOSITORIO.UNESP.BR/BITSTREAM/ HANDLE/11449/145853/ISSN21769761-2011-06-250.PDF?SEQUENCE=1. ACESSO EM: 10 ABR. 2020.

SilVA, C. C. F. M e. 2019. Sexualidade feminina na trama do tempo: narRativas indizíveis por mulheres invisíveis. Tese (Doutorado em Psicologia). Universidade Estadual Paulista "Júlio de Mesquita Filho", Faculdade de CiênCIAS E Letras de Assis, 2019. 153 F. DisPonível EM: htTP://hDL. HANDLE. NET/11449/191278. ACESSO EM: 15 ABR. 2020.

SILVA, L. R. F. DA VELHICE À TERCEIRA IDADE: O PERCURSO HISTÓRICO DAS IDENTIdades atreladas ao processo de enVelhecimento. História, CiênCias, Saúde - Manguinhos, Rio de JaneiRo, v. 15, N. 1, P. 155-168, Jan.-Mar. 2008. 
O Projeto De Extensão Unati-Assis Em Perspectiva: Trajetória, Desenvolvimento E Ações Kátia Rodrigues Mello Miranda • Laura Pagnan Condini, et al...

DisPonível EM: HTTPS://WwW.SCIELO.BR/PDF/hCSM/v15N1/09.PDF. ACESSO EM: 15 ABR. 2020.

SILVA, N. P. et al. VelHice, IMAgem e APARêNCIA: A eXPeriêNCIA DE IDOSOS da UnATI EACH-USP. Revista Kairós-Gerontologia, v. 15, 2012, P. 235-257. DISPONÍVEL EM: HTTPS://REVISTAS.PUCSP.BR/KAIROS/ARTICLE/ VIEW/15251/30510. ACESSO EM: 07 ABR. 2020.

SOARES, M. R. P.; ISTOE, R. S. C. Alfabetização E InClusÃo de pessoas IDOSAS: UMA PROPOSTA INTERDISCIPLINAR MEDIADA PELAS TECNOLOGIAS DA INFORmação e da comunicaÇão. ReVista Científica Interdisciplinar, N. 3. v. 2, JUL./SET. 2015. DISPONÍVEL EM: HTTP://REVISTA.SRVROOT.COM/LINKSCIENCEPLACE/ INDEX.PHP/LINKSCIENCEPLACE/ARTICLE/VIEW/123/62. ACESSO EM: 07 ABR. 2010.

\section{4}

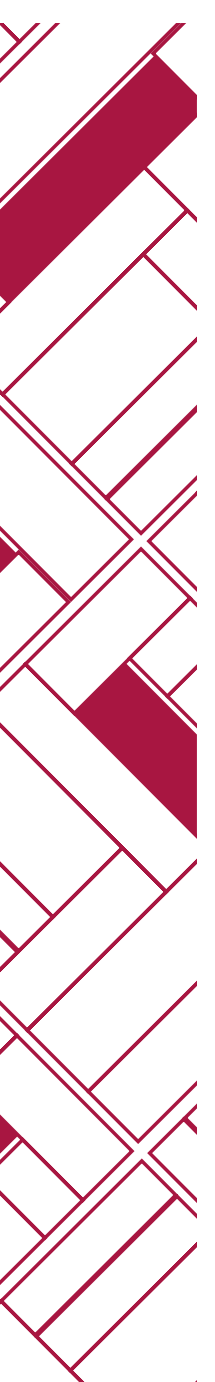

